\title{
REVIEWS AND COMMENTS
}

\begin{abstract}
With the intent of stimulating discussion, this section is reserved for book reviews, comments, and letters; your input is welcome. By nature, this material may be subjective, reflecting the opinions of the authors; your responses are therefore encouraged. 1991 Academic Press. Inc.
\end{abstract}

Bargaining and Markets. By Martin J. Osborne and Ariel Rubinstein, Academic Press, San Diego, 1990. ISBN 0-12-528631-7, xi + 216 pp., \$14.95 Paper, \$34.50 hardbound.

I recall speaking on bargaining theory in the late seventies and being told by more than one unreceptive audience that "bargaining is not part of economics." The publication of this book makes it clear how far we have come since those barbaric times.

In the seventies, bargaining theory was an esoteric branch of cooperative game theory. Those with metaphysical leanings, who nowadays would invent refinements of Nash equilibrium, would then invent abstract axiom systems for "cooperative solution concepts." The properties of these systems were then investigated with little or no concern for the applicability of the ideas under study. Questions about the circumstances in which the axioms might apply were brushed aside. Are your axioms principles of social justice? Do they describe what a fair arbitrator would do? Are they an attempt to characterize the bargaining behavior of actual people? Or do you follow Nash in regarding the axioms as being about optimal bargaining between rational agents? If so, what are the circumstances in which the rational agents bargain? Who can do what and how can they do it? Not only were such questions left unanswered, but a virtue was made of not answering them. So long as one avoids committing oneself to a specific interpretation of a set of abstract assumptions, the conclusions can be represented as being very "general." Remnants of this attitude still survive. It remains commonplace to argue that the advantage of working with cooperative game theory is that it yields results of great generality, whereas the conclusions of noncooperative theory are very special to the extensive form examined. But, if two slightly different extensive forms lead to sharply different predictions of the bargaining 
outcome, how can there be a "general" result? Things abstracted away in the cooperative formulation clearly matter, and ignoring them will necessarily be fatal to any prospects of realistic application. In any case, it is perhaps no wonder that hard-nosed, practical economists felt that the activities of bargaining theorists of the time had no relevance to their concerns. Although, how a hard-nosed, practical economist could convince himself that bargaining itself has no relevance to economics remains a mystery.

Nash $(1950,1951,1953)$ had already pointed the right way forward in his pioneering papers of the early fifties. Although his axiom system was, and continues to be, widely misinterpreted, he took the orthodox, neoclassical position that one should study optimizing behavior by rational agents. He therefore never intended to be the architect of a fair arbitration scheme. His view, nowadays widely honored under the name of the Nash Program, was that an axiom system like his is useful to the extent that it predicts the equilibrium outcomes of suitable noncooperative bargaining models. Others, of course, had sought to study the process by means of which people bargain their way to agreements. More were to do so later. Zeuthen (1930), especially as interpreted by Harsanyi (1977), is very modern in spirit. Hicks' (1934) attempt to model wage negotiation is very sketchy by comparison, ${ }^{1}$ although it received a lot more attention. This work, and the later work of Bishop (1963), Foldes (1964), and others, incorporated behavioral assumptions that are difficult to evaluate. Harsanyi (1977), Selten (see Harsanyi (1977)), and Ståhl (1972) were among the first, apart from Nash himself, to look seriously at the equilibria of bargaining problems modeled as noncooperative games. However, for various reasons, these preliminary explorations did not capture the imagination of the profession. It was not until Rubinstein's (1982) alternating offer model appcared that the subject took off.

The model is very natural. Players exchange offers until agreement is reached. The incentive to reach agreement early is simply that the bargainers prefer an agreement now to the same agreement tomorrow. ${ }^{2}$ The conclusion that a unique subgame-perfect equilibrium exists under mild conditions is very encouraging, and the fact that the equilibrium outcome can be characterized in terms of an (asymmetric) Nash bargaining solution is an attention-grabber.

A list of the papers that exploit Rubinstein's breakthrough would be long indeed. However, Osborne and Rubinstein's book makes no attempt

${ }^{1}$ Indeed, I have never been able to make proper sense of it. If one computes his "concession curves" for the Rubinstein model, they do not cross at all.

${ }^{2}$ As Cross (1969) puts it, "If it didn't matter when the parties agreed, it wouldn't matter whether they agreed at all." 
to survey the field. They try instead to chronicle the successes and the failures by looking at the simplest possible models that capture the considerations that matter. The successes are important, but let us first consider the big failure.

When I first met Rubinstein, he told me that he had been working on the bargaining problem, but had been unable to get anywhere. This turned out to mean that he had not been able to make any progress with the problem of incomplete information. It is perhaps controversial to say so, but my own view is that we are not really any farther on than we were then. Historically, the impetus to invent refinements of Nash equilibrium largely derived from the discovery that bargaining models of incomplete information usually have innumerable equilibria. But the refinement literature is not a success. It is a lame duck when applied to simple models, but realistic models of bargaining with incomplete information are seldom simple. This is not to say that the refinement literature is devoid of insights. The problem is that we do not know which of all the bewildering array of ideas are insightful and which are not.

I would not therefore recommend reading Osborne and Rubinstein's Chapter 5 with a view to learning how to cope with real-life bargaining problems of incomplete information. As an introduction to the type of problems in response to which refinement theory was created, it is magnificent, although not easy reading for a beginner. The sections on mechanism design and its applications in bargaining will also be found instructive. However, the heart of the book is elsewhere.

So much for the big failure of modern bargaining theory. What of its successes? The most important success, treated in Chapter 4 , is in making it clear what aspects of the environment a modeler needs to take into account in predicting bargaining outcomes. When are threats credible? What arc the bargaincrs' outside options? What are the different ways in which the negotiations might break down? Studying these questions in specific noncooperative models provides general insights that can be used to determine how and when to make use of given cooperative solution concepts in an applied model. In particular, it is seldom appropriate to use the Nash bargaining solution, as was once standard practice, with the players' disagreement utilities set equal to their outside options.

However, what the book is mostly about is the relationship between bargaining theory and the operation of markets. In some markets, the price is determined by a centralized auctioning mechanism. In others, like the market for houses, the mechanism is highly decentralized. Each house that is sold is bargained over. The bargain that is struck will depend on various factors. In particular, it will depend on the price at which other comparable houses are selling. The aim of Bargaining and Markets is to describe the basis of a viable theory of such a decentralized pricing mech- 
anism, building on the insights of the well-known paper of Rubinstein and Wolinsky (1985).

In brief, buyers and sellers search until they find a partner. Once a buyer and a seller are matched, they bargain. The result of the bargaining is determined by two considerations: the impatience of the agents, and their fear of losing their current bargaining partner if their demands are too obdurate. A noncooperative approach allows the construction of clean models that often have a unique equilibrium.

An immediate question of interest is the extent to which the markets studied satisfy the Walrasian paradigm when the imperfections become negligible. Gale (1986a,b, 1987) has done sterling service on this issue, and the book does a good job of getting across the essential ideas without becoming overtechnical. However, although the provision of proper microfoundations for the use of Walrasian ideas in decentralized markets is clearly of major importance, it is not, as one sometimes hears said, the only reason that search-and-bargaining models deserve study. It seems to me that the prospect of learning about the operation of markets in which imperfections are not negligible is very much more exciting. In many markets, frictions or transaction costs are far from negligible, and there is much mileage to be gained from getting a handle on how different types of friction should be anticipated to distort the going price. However, although his question is wide-open and the tools for its investigating are on the table, the opportunities for progress have yet to be fully exploited. Perhaps the reason is that the attention of those who know the field is continually diverted to the incomplete information problem.

However, there is room for hope that Osborne and Rubinstein's userfriendly book will open up the area to workers whose interests are primarily practical. Having used it to teach from, I can vouch for the fact that, with the exception of Chapter 5, it is well within the reach of graduate students whose interests are not primarily theoretical, and whose mathematical sophistication is less than optimal. The authors have no time for airy generalities. They concentrate on communicating the essentials using the simplest possible models, which are explained carefully in full detail. This is a well-written book on an important topic. Everyone should run out and buy a copy.

Ken Binmore ${ }^{3}$

Department of Economics

University of Michigan

Ann Arbor, Michigan 48109

${ }^{3}$ Address from January 2, 1991, to July 31, 1991: Department of Economics, University College London, Gower Street, London WC1E 6BT, England. 


\section{REFERENCES}

Bishop, R. (1963). "Game-Theoretic Analyses of Bargaining," Quart. J. Econ. 77, 559-602.

CRoss, J. (1969). The Economics of Bargaining. New York: Basic Books.

FoldDEs, L. (1964). "A Determinate Model of Bilateral Monopoly," Economica 31, 117131.

GALE, D. (1986a). "Bargaining and Competition, Part I, Characterization," Econometrica $54,785-806$.

Gale, D. (1986b). "Bargaining and Competition, Part II, Existence," Econometrica 54, 807-818.

Gale, D. (1987). "Limit Theorems for Markets with Sequential Bargaining," J. Econ. Theory 43, 20-54.

HARSANYI, J. (1977). Rational Behavior and Bargaining Equilibrium in Games and Social Situations. Cambridge: Cambridge Univ. Press.

Hicks, J. (1934). The Theory of Wages. London: Macmillan \& Co.

NASH, J. (1950). "The Bargaining Problem," Econometrica 18, 155-162.

NaSH, J. (1951). "Non-cooperative Games," Ann. Math. 54, 286-295.

NaSH, J. (1953). "Two-Person Cooperative Games," Econometrica 21, 128-140.

Rubinstein, A. (1982). "Perfect Equilibrium in a Bargaining Model," Econometrica 50, 97-109.

Rubinstein, A., AND Wolinsky, A. (1985). "Equilibrium in a Market with Sequential Bargaining," Econometrica 53, 1133-1150.

Stahl, I. (1972). Bargaining Theory. Stockholm: Economics Research Institute.

Zeuthen, F. (1930). Problems of Monopoly and Economic Warfare. London: Routhledge \& Kegan Paul. 